\title{
Lanostane-type triterpenes from the sporoderm-broken spores of Ganoderma lucidum
}

\author{
Bing-Ji Ma, Yan Zhou, Yuan Ruan, Jin-Chuan Ma, Wei Ren and Chun-Nan Wen
}

The Journal of Antibiotics (2012) 65, 165-167; doi:10.1038/ja.2011.135; published online 11 January 2012

Keywords: Ganoderma spores; lucialdehyde E; triterpene

The fruiting bodies of Ganoderma lucidum are widely used in China, Japan and Korea as medicine for a variety of diseases, such as chronic bronchitis inflammation, hyperlipidemia, hypertension, neurasthenia, hepatitis, leukopenia and adjuvant treatment of cancers. ${ }^{1,2}$ Ganoderma spores is the fungus's reproductive cells ejected from the cap of G. lucidum after the fruiting bodies become mature. In recent years, with the development of spores collection, sporoderm-broken technology and application of modern analytical instruments, there has been some progress on chemical constituents, pharmacological effects and mechanisms of action of Ganoderma spores. Moreover, the increasing publications in domestic and international suggest the important bioactivities of the spores of G. lucidum.,

The chemical constituents and bioactivities of the fruiting bodies of G. lucidum have been fully investigated, and $>150$ triterpenes have been reported from the fruiting bodies of G. lucidum representing five major structural classes. ${ }^{5-7}$ However, the chemical investigation of the spores of G. lucidum can only be traced to $1988 .{ }^{8}$ Up to now, a series of new lanostane-type triterpenes, such as ganosporelactones $\mathrm{A}, \mathrm{B},{ }^{9}$ lucidumol $A$, ganoderic acid $\beta,{ }^{10}$ ganoderic acid $\gamma, \delta, \varepsilon, \xi, \eta, \theta^{11}$ and lucidenic acid SP, ${ }^{12}$ were isolated from the spores of G. lucidum.

Sporoderm-broken technology recently has been applied to Ganoderma spores to improve the extraction rate and improve the remedy effect in the clinical trials. ${ }^{13}$ However, to the best of our knowledge, an article on the chemistry of the compounds isolated from the sporoderm-broken spores of G. lucidum has not been prepared. As a part of our continuing studies to find novel bioactive compounds from mushroom, we found a new highly oxygenated lanostane-type triterpene aldehyde, lucialdehyde E (1) from the sporoderm-broken spores of G. lucidum, together with seven known triterpenes, lucialdehyde D (2), ganodermanondiol (3), ganoderic acid $\mathrm{C}_{1}(4)$, ganodermanontriol (5), genoderic acid $\xi(6)$, ganoderic acid A (7) and lucidumol A (8) (Figure 1). The structural elucidations of all the compounds were based on the spectroscopic evidences and comparing with literature data. Lanostane-type triterpene aldehydes are very few in the Gano- dermataceae, only lucialdehydes A-C and lucialdehyde D were isolated from the fruiting bodies of G. lucidum and G. pfeifferi, respectively. ${ }^{14,15}$ Compound $\mathbf{1}$ is a lanostane-type triterpene aldehyde isolated from the sporoderm-broken spores of G. lucidum for the first time. The cytotoxicity of compounds 1-8 was tested in vitro against esophageal tumor EC109 cell line by 3-(4,5-dimethylthiazol-2-yl)-2,5-diphenyltetrazolium bromide assay. Compounds 1, 2, 3, 4 and 7 showed significant cytotoxic activity with $\mathrm{IC}_{50}$ values of 18.7, 21.4, 16.2 and $20.1 \mu \mathrm{g} \mathrm{ml}^{-1}$, respectively. In addition, the other four triterpenes only showed weak cytotoxic activity with $\mathrm{IC}_{50}$ values of $124.8,162.6,148.1$ and $121.5 \mu \mathrm{g} \mathrm{ml}^{-1}$, respectively.

Lucialdehyde E (1) was obtained as a white amorphous powder, with a positive optical rotation, $[\alpha]_{\mathrm{D}}^{20}+137^{\circ}\left(\mathrm{CHCl}_{3}\right)$. The presence of two conjugated carbonyl groups $\left(1668\right.$ and $\left.1660 \mathrm{~cm}^{-1}\right)$ was suggested by IR spectrometry. The high-resolution electron impact mass (HREIMS) spectrum of 1 give an ion peak at $m / z 484.3106$ (calculated for 484.3114) and corresponded to a molecular formula of $\mathrm{C}_{30} \mathrm{H}_{44} \mathrm{O}_{5} \cdot{ }^{1} \mathrm{H}$ NMR spectrum of 1 showed signals for seven methyls, and a singlet at $\delta 9.41$ for an aldehyde proton (Table 1 ). The ${ }^{13} \mathrm{C}$-NMR spectrum of 1 demonstrated signals characteristic for seven methyls, four olefinic carbons, two oxymethylene carbons ( $\delta$ 68.6, 72.1), and an aldehyde carbon $\left(\delta\right.$ 194.4). The ${ }^{13} \mathrm{C}-\mathrm{NMR}$ spectrum of 1 was close to the structure of ganoderic acid $\gamma,{ }^{11}$ except for chemical shifts of C-26 ( $\delta$ 194.4 in lucialdehyde $\mathrm{E}$ vs $\delta 170.2$ in ganoderic acid $\gamma$ ) and C-23 ( $\delta 26.0$ in lucialdehyde $\mathrm{E}$ vs $\delta 65.9$ in ganoderic acid $\gamma$ ). HMBC correlations were observed between signals of $\mathrm{H}-5$ and $\mathrm{C}-7$; H-30 and C-8; H-19 and C-9, 11; H-17 and C-15; H-18 and C-11, 12. In addition, HMBC correlations between signals of $\mathrm{H}-22$ and C-24 (an olefinic carbon at $\delta$ 156.3), and between signals of $\mathrm{H}-24$ and C-26, as well as those of $\mathrm{H}-24$ and $\mathrm{C}-27$ revealed a conjugated aldehyde at C-24-C-26 in the side chain. As the signals of H-28 and H-29 were shift-correlated with that of C-3, a carbonyl group was concluded to be at C-3 (Figure 2). Two equatorial hydroxyl groups at C-7 ( $\beta$-orientation) and C-15 ( $\alpha$-orientation) were deduced from the 


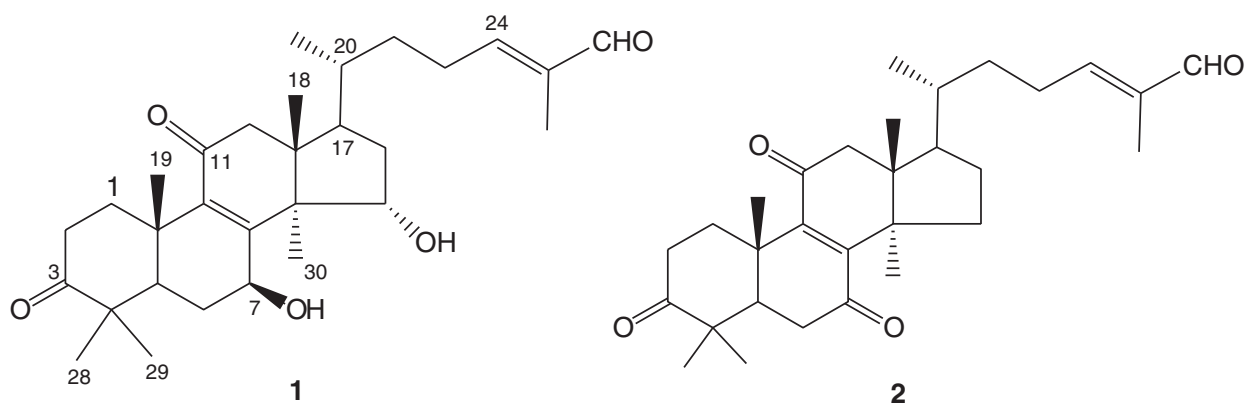

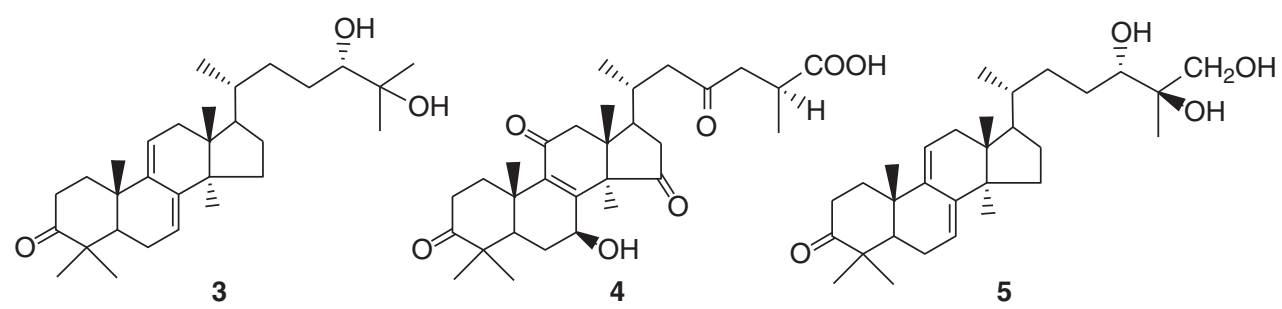

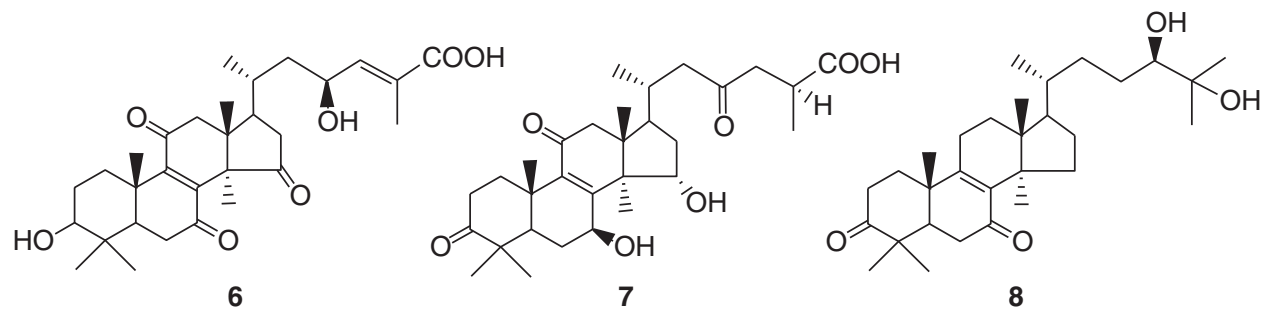

Figure 1 Structures of triterpenes 1-8.

multiplicities of $\mathrm{H}-7$ and $\mathrm{H}-15$, which was supported by NOE correlations observed from $\mathrm{H}-7$ to $\mathrm{H}-5, \mathrm{H}-29$ and $\mathrm{H}-30$. NOE correlations were also observed from $\mathrm{H}-15$ to $\mathrm{H}-18, \mathrm{H}-19$, and $\mathrm{H}-19$ to H-28. As NOE correlations were observed between H-24 and $\mathrm{H}-26$, the configuration of $\mathrm{C}-24$ was suggested to be $E$ with respect to an aldehyde group, which was also supported by comparing to the NMR spectral data of ganoderal A having a (24E)-26-al moiety. ${ }^{16}$ These data above suggested a highly oxygenated lanostane-type Ganoderma triterpene, consequently, the structure of 1 was determined as $7 \beta, 15 \alpha$-dihydroxyl-3, 11-dioxo-5 $\alpha$-lanosta-8, 24-dien-26-al.

Some progresses of chemical and pharmacological research have been made on the spores of G. lucidum. In some cases, extracts of partly purified preparations and pure compounds from Ganoderma spores have been used for in vitro or in vivo testing. ${ }^{17,18}$ However, as the biological activities of Ganderma spores are determined by the active ingredients contained, the levels of active ingredients vary from the origin, cultivation, acquisition time and extraction methods. ${ }^{19}$

At present, the spores of G. lucidum have been widely used in China as a home remedy for the adjuvant treatment of cancers, and its medical value has been widely recognized, however, its biological activities still need further assessment before they can be accepted not only by the traditional Asian medicine, but also by the west science and medicine.

\section{EXPERIMENTAL PROCEDURE}

\section{General}

$[\alpha]_{D}$ was carried out on JASCO-20 polarimeter. IR spectra were obtained on a Bio-Rad FTS-135 IR spectrometer in KBr pellets (Bio-Rad, Philadelphia, PA,

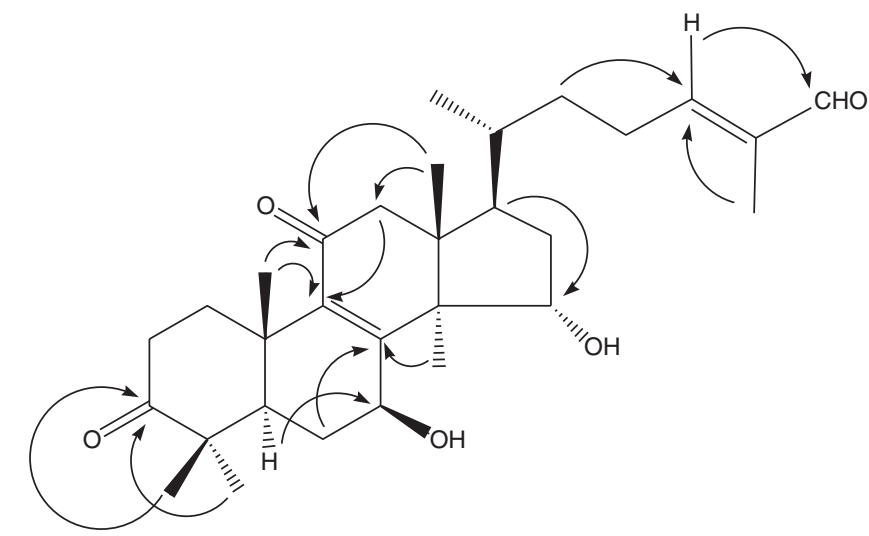

Figure 2 Key HMBC correlations of lucialdehyde E.

USA). ${ }^{1} \mathrm{H},{ }^{13} \mathrm{C}$ NMR and 2D NMR spectra were recorded on a Bruker AM-400 and DRX-500 instruments (Bruker, Fällanden, Switzerland). Chemical shifts are given as $\delta$ in p.p.m. relative to tetramethylsilane as internal standard and coupling constants in $\mathrm{Hz}$. Mass spectra were measured with a VG Autospec 3000 mass spectrometer (VG, Manchester, UK).

\section{Mushroom material}

The sporoderm-broken spores of G. lucidum were purchased from Zhengzhou market of Henan Province, People's Republic of China, in August 2010. The fungal identification was made by Professor Jin-Wen Shen, Henan Agricultural University. A dried specimen was deposited in the Herbarium of Henan Agricultural University. 
Table $1{ }^{1} \mathrm{H}$ and ${ }^{13} \mathrm{C}$ NMR data of lucialdehyde $\mathrm{E}$ in $\mathrm{CDCl}_{3}$

\begin{tabular}{|c|c|c|}
\hline Position & $\delta C$ & $\delta H$ \\
\hline 1 & 35.2 & $1.63(1 \mathrm{H}, \mathrm{m}), 2.72(1 \mathrm{H}, \mathrm{m})$ \\
\hline 2 & 34.1 & $2.34(1 \mathrm{H}, \mathrm{m}), 2.86(1 \mathrm{H}, \mathrm{m})$ \\
\hline 3 & 218.4 & \\
\hline 4 & 45.9 & \\
\hline 5 & 48.6 & $1.99(1 \mathrm{H}, \mathrm{m})$ \\
\hline 6 & 28.8 & $1.82(1 \mathrm{H}, \mathrm{m}), 2.45(1 \mathrm{H}, \mathrm{m})$ \\
\hline 7 & 68.6 & $4.93(1 \mathrm{H}, \mathrm{dd}, 9.8,6.8)$ \\
\hline 8 & 159.8 & \\
\hline 9 & 140.3 & \\
\hline 10 & 37.5 & \\
\hline 11 & 199.8 & \\
\hline 12 & 51.6 & $2.23(1 \mathrm{H}, \mathrm{m}), 2.75(1 \mathrm{H}, \mathrm{m})$ \\
\hline 13 & 46.2 & \\
\hline 14 & 53.7 & \\
\hline 15 & 72.1 & $4.68(1 \mathrm{H}, \mathrm{m})$ \\
\hline 16 & 36.2 & $2.01(2 \mathrm{H}, \mathrm{m})$ \\
\hline 17 & 47.5 & $1.50(1 \mathrm{H}, \mathrm{m})$ \\
\hline 18 & 17.0 & $0.92(3 \mathrm{H}, \mathrm{s})$ \\
\hline 19 & 19.3 & $1.27(3 \mathrm{H}, \mathrm{s})$ \\
\hline 20 & 35.9 & $1.78(1 \mathrm{H}, \mathrm{m})$ \\
\hline 21 & 18.4 & $1.13(3 \mathrm{H}, \mathrm{d}, 6.3)$ \\
\hline 22 & 34.4 & $1.46(2 \mathrm{H}, \mathrm{m}), 1.82(1 \mathrm{H}, \mathrm{m})$ \\
\hline 23 & 26.0 & $2.10(1 \mathrm{H}, \mathrm{m}), 2.34(1 \mathrm{H}, \mathrm{m})$ \\
\hline 24 & 156.3 & $6.33(1 \mathrm{H}, \mathrm{m})$ \\
\hline 25 & 138.6 & \\
\hline 26 & 194.4 & $9.41(1 \mathrm{H}, \mathrm{s})$ \\
\hline 27 & 9.2 & $1.93(3 \mathrm{H}, \mathrm{s})$ \\
\hline 28 & 20.8 & $1.25(3 \mathrm{H}, \mathrm{s})$ \\
\hline 29 & 27.5 & $0.95(3 \mathrm{H}, \mathrm{s})$ \\
\hline 30 & 19.1 & $0.92(3 \mathrm{H}, \mathrm{s})$ \\
\hline
\end{tabular}

\section{Chemicals}

Column chromatography was carried out on silica gel (200-300 mesh), and TLC was carried out on plates precoated with silical gel $\mathrm{F}_{254}$ (Qingdao Marine Chemical Ltd., Qingdao, PR China) and Sephadex LH-20 (Amersham Biosciences, Uppsala, Sweden). Fractions were monitored by TLC and spots were detected by spaying $10 \%$ sulfuric acid in ethanol followed by heating.

\section{Isolation procedure}

The sporoderm-broken spores of G. lucidum $(8.0 \mathrm{~kg})$ was extracted with a mixed solvent of $\mathrm{CHCl}_{3}-\mathrm{MeOH}(50: 50 \mathrm{v} / \mathrm{v}, 20 \mathrm{~L} \times 3)$ at room temperature, and the combined solutions were evaporated in vacuo to give a residue $(462.8 \mathrm{~g})$. The residue was suspended in $90 \% \mathrm{MeOH}(1000 \mathrm{ml})$ and extracted with hexane $(600 \mathrm{ml} \times 2)$. The residual $\mathrm{MeOH}$ solution was concentrated in vacuo to give a residue ( $414.2 \mathrm{~g}$ ), which was applied to a column chromatography of silica gel. Elution was started with $\mathrm{CHCl}_{3}$, and then $\mathrm{CHCl}_{3}-\mathrm{MeOH}(9$ : $1, \mathrm{v} / \mathrm{v}$ ) to yield two fractions (A: $122.0 \mathrm{~g}, \mathrm{~B}: 85.5 \mathrm{~g}$ ). Column chromatography of fraction A on silica gel (petroleum ether-EtOAc, $5: 1 \rightarrow 1: 1, \mathrm{v} / \mathrm{v}$ ) yielded five subfractions (A1-A5; 9.8, 13.5, 25.4, 24.6 and 16.8 g, respectively). The subfraction Al was submitted to repeated column chromatography on silica gel by eluting with hexane-acetone $(5: 1, \mathrm{v} / \mathrm{v})$ and repeated Sephadex LH$20\left(\mathrm{CHCl}_{3}-\mathrm{MeOH}, 1: 1, \mathrm{v} / \mathrm{v}\right)$, followed by preparative HPLC (a linear gradient of $\mathrm{CH}_{3} \mathrm{CN}(75 \% \rightarrow 95 \%)$ in $2 \% \mathrm{AcOH}$, flow rate $5 \mathrm{ml} \mathrm{min}^{-1}$, detection at $235 \mathrm{~nm})$ to afford compounds 2 (14.6 mg), $3(9.8 \mathrm{mg}), \mathbf{1}(15.9 \mathrm{mg})$ and 5
(10.2 mg). The subfraction A2 was further purified by column chromatography on silica gel (hexane-acetone, $4: 1, \mathrm{v} / \mathrm{v}$ ) and repeated Sephadex LH-20 $\left(\mathrm{CHCl}_{3}-\mathrm{MeOH}, 1: 1, \mathrm{v} / \mathrm{v}\right)$, followed by preparative HPLC (a linear gradient of $\mathrm{CH}_{3} \mathrm{CN}(72 \% \rightarrow 90 \%)$ in $2 \% \mathrm{AcOH}$, flow rate $6 \mathrm{ml} \mathrm{min}^{-1}$, detection at $230 \mathrm{~nm})$ to afford compounds $8(11.7 \mathrm{mg}), 6(20.1 \mathrm{mg}), 4(22.7 \mathrm{mg})$ and 7 (19.6 mg).

\section{Cell growth inhibition assay}

The growth inhibitor concentrations of compounds 1-8 on esophageal cancer EC109 cell line were determined by 3-(4,5-dimethylthiazol-2-yl)-2,5-diphenyltetrazolium bromide assay. ${ }^{20}$ The EC109 cell was exposed to compounds at $0.01,0.1,1,10$ and $100 \mathrm{mgl}^{-1}$ concentrations and each concentration was tested in triplicate. The OD was measured with a microplate reader at $570 \mathrm{~nm}$.

\section{ACKNOWLEDGEMENTS}

The authors gratefully acknowledge the staffs of the analytical group at Zhengzhou University for measuring the spectral data and the Open Foundation of State Key Laboratory of Phytochemistry and Plant Resources in West China (P2010-KF06).

1 Bojana, B., Marin, B., Zhang, J. S. \& Lin, Z. B. Ganoderma lucidum and its pharmaceutically active compounds. Biotech. Ann. Rev. 13, 265-301 (2007).

2 Jong, S. C. \& Birmingham, J. M. Medicinal benefits of the mushroom Ganoderma. Adv. Appl. Microb. 37, 101-134 (1992).

3 Lin, Z. B. \& Wang, P. Y. The pharmacological study of Ganoderma spores and their active compounds. J. Peking Univ. (Health Sciences) 38, 541-547 (2006).

4 Zhang, W. \& Zeng, Y. S. Progress on the spores of Ganoderma lucidum. J. Chin. Integr. Med. 2, 463-465 (2004).

5 Chen, R. Y. \& Yu, D. Q. Progress on triterpenoids of Ganoderma lucidum. Acta Pharm. Sin. 25, 940-953 (1990).

6 Luo, J. \& Lin, Z. B. Advances of pharmacological effects of triterpenes from Ganoderma lucidum. Acta Pharm. Sin. 37, 574-578 (2002).

7 Qiao, Y., Yang, Y. K., Dong, X. C. \& Qiu, M. H. ${ }^{13} \mathrm{C}$ NMR chemical shifts of Ganoderma triterpenoids: a meta-analysis. Chin. J. Mag. Res. 22, 437-456 (2005).

8 Hou, C. Y., Sun, Y. T., Yan, L. \& Xue, H. Studies on the chemical constituents of the spores from Ganoderma lucidum. Acta Bot. Sin. 30, 66-70 (1988).

9 Chen, R. Y. \& Yu, D. Q. Application of 2D NMR techniques in the structure determination of ganosporelactone A and B. Acta Pharm. Sin. 26, 430-436 (1991).

10 Min, B. S., Nakamura, N., Miyashiro, H., Bar, K. W. \& Hattori, M. Triterpenes from the spores of Ganoderma lucidum and their inhibitory activity against HIV-1 protease. Chem. Pharm. Bull. 46, 1607-1612 (1998).

11 Min, B. S., Gao, J. J., Nakamura, N. \& Hattori, M. Triterpenes from the spores of Ganoderma lucidum and their cytotoxicity against meth-A and LLC tumor cells. Chem. Pharm. Bull. 48, 1026-1033 (2000).

12 Min, B. S., Gao, J. J., Hattori, M., Lee, H. K. \& Kim, H. Y. Anticomplement activity of triterpenoids from the spores of Ganoderma lucidum. Planta Med. 67, 811-814 (2001).

13 Zhu, H. S., Yang, X. L., Wang, L. B., Zhao, D. X. \& Chen, L. Effects of extracts from sporoderm-broken spores of Ganoderma lucidum on Hela cells. Cell Biol. Toxicol. 16, 201-206 (2000).

14 Gao, J. J. et al. New triterpene aldehydes, lucialdehydes A-C, from Ganoderma lucidum and their cytotoxicity against murine and human tumor cells. Chem. Pharm. Bull. 50, 837-840 (2001).

15 Niedermeyer, T. H. J. et al. Antiviral terpenoid constituents of Ganoderma pfeifferi. J. Nat. Prod. 68, 1728-1731 (2005).

16 Morigiwa, A., Kitabatake, K., Fujimoto, Y. \& Ikekawa, N. Angiotensin converting enzyme-inhibitory triterpenes from Ganoderma lucidum. Chem. Pharm. Bull. 34, 3025-3028 (1986)

17 Sliva, D., Sedlak, M. \& Slivova, V. Biologic activity of spores and dried powder from Ganoderma lucidum for the inhibition of highly invasive human breast and prostate cancer cells. J. Alter. Compl. Med. 9, 491-497 (2003).

18 Liu, Q. Y., Sartippour, M. R. \& Brooks, M. N. Ganoderma lucidum spore extract inhibits endothelial and breast cancer cells in vitro. Oncol. Rep. 12, 659-662 (2004).

$19 \mathrm{Ma}$, L., Wu, F. \& Chen, R. Y. Analysis of triterpene constituents from Ganoderma lucidum. Acta Pharm. Sin. 38, 50-52 (2003).

$20 \mathrm{Ma}, \mathrm{B}$. J. et al. Cytotoxic aromatic compounds from Hericium erinaceum. J. Antibiot. 63, 713-715 (2010). 